\section{Brazilian Journal \\ of Chemical \\ Engineering}

ISSN 0104-6632

Printed in Brazil

www.scielo.br/bjce

Vol. 35, No. 01, pp. 253 - 264, January - March, 2018

(cc) BY

dx.doi.org/10.1590/0104-6632.20180351s2016578

\title{
COMPETITIVE ADSORPTION OF DYE SPECIES ONTO BIOMASS NANOPOROUS CARBON IN SINGLE AND BICOMPONENT SYSTEMS
}

\author{
Huijing $\mathrm{Yu}^{1}$, Tingting $\mathrm{Wang}^{1}$, Wei Dai ${ }^{1, *}$, Le $\mathrm{Yu}^{1}$ and $\mathrm{Na} \mathrm{Ma}{ }^{2, *}$ \\ ${ }^{1}$ Key Laboratory of the Ministry of Education for Advanced Catalysis Materials, College of Chemistry and Life Science, \\ Zhejiang Normal University, Zhejiang Province Jinhua 321004, People's Republic of China \\ ${ }^{2}$ College of Geography and Environmental Science, Zhejiang Normal University, \\ Zhejiang Province Jinhua 321004, People's Republic of China
}

(Submitted: January 26, 2016; Revised: October 7, 2016; Accepted: November 23, 2016.)

\begin{abstract}
We first present a cost-effective approach to simultaneously dispose of rutaceae plant waste (the discarded peels of orange, finger citron, pomelo and lemon) to yield biomass nanoporous carbons (BNCs). The adsorption of orange II (OII) and acid chrome blue K (ACBK) from aqueous solutions in single and binary dye systems by four types of BNCs were studied in a batch adsorption system. The adsorption studies include both equilibrium adsorption isotherms and kinetics. Four adsorption models for predicting the multicomponent equilibrium sorption isotherms have been compared in order to determine which one is the best fit model to predict or correlate binary adsorption data. The kinetic data were well described by the pseudo-second-order kinetic model. It was found that the adsorption capacity of orange peel-based nanoporous carbon (OPC) is much higher than those of the other types of BNCs. In addition, OPC also shows higher OII uptake capacities from binary dye solutions. The four types of BNCs could be employed as a low-cost alternative for the removal of textile dyes from effluents.

Keywords: Competitive Adsorption; Batch processing; Waste-water treatment; Azo dyes
\end{abstract}

\section{INTRODUCTION}

Nanostructured carbon materials have attracted tremendous attention in that they possess remarkable properties and exhibit promising potential in a variety of important application areas related to sensing (Kharat et al., 2015), adsorption (Gong et al., 2013), catalysis (Sun et al., 2013), and energy conversion/storage (Hu et al., 2013). Meanwhile, in parallel with the aggravating energy and environmental problems such as pollution, fossil fuel depletion and global warming rise, interests in clean and renewable energy materials, as well as their devices have spiked in recent years. As a renewable access and environmental friendliness. Therefore, nanoporous carbon materials obtained from biomass have been explored with sources as diverse as watermelon (Wu et al., 2013), hemp fiber (Wang et al., 2013), banana peel (Lv et al., 2012), bacterial fiber (Wu et al., 2014), and so on. As the members of rutaceae plants, orange, pomelo, lemon and finger citron are favorite health food, but a lot of waste peels are produced during daily life and by the food industry. The four types of waste peels are natural, abundantly available, and yearly renewable biomass sources. As solid waste materials, most of the peels (approximately 2 hundred millions tons annually in China alone) (Dai et al., 2010) are still

\footnotetext{
* Corresponding authors: Wei Dai. E-mail: daiwei@zjnu.edu.cn. Fax: +86-579-82282531. Tel: +86-579-82282269; Na Ma. E-mail: mana@zjnu.cn. Fax: +86-579-82282531. Tel: +86-579-82282269.
} 
source, biomass resources have attracted a great deal of attention in the preparation of carbon materials, because of its low value, huge amount, rapid regeneration, easy become an important issue that needs to be solved imperiously. Biomass usually possesses natural plant fiber structure and this structure could provide an opportunity to prepare nanoporous carbon materials (Wu et al., 2013). Low-cost carbon materials prepared from the other biomass byproducts and waste materials have been investigated for a long time (Wu et al., 2013; Wang et al., 2013; Lv et al., 2012; Wu et al., 2014). The aim behind using waste materials as an alternative low-cost precursor to prepare nanoporous carbon materials is that it will provide a twofold advantage with respect to environmental pollution. On one hand, the huge volume of waste materials could be partly reduced and help reduce the cost of waste disposal. On the other hand, the low-cost adsorbent, if developed, can provide a potentially inexpensive raw material for commercial nanoporous carbon and reduce the pollution of wastewaters at a reasonable cost.

In the last decade, removal of azo dyes from waste water has attracted considerable attention because of their long-term environmental toxicity and short-term public health damage (Ofomaja and Ho, 2008). Among these azo dyes, orange II (OII) and acid chrome blue $\mathrm{K}$ (ACBK) have wide applications in paper coloring, temporary hair colorant, dying cottons and wools ( $\mathrm{Hu}$ et al., 2014). They can cause some harmful effects in humans such as eye burns, dysfunction of kidney, cyanosis, convulsions, tachycardia, dyspnea and, irritation to the skin (Gong et al., 2013; Hu et al., 2014). Therefore, removal of OII and ACBK from wastewater and/or process effluent has become one of the major environ- burned directly in the field or disposed as garbage, causing serious environmental pollution. Therefore, the consumption and application of these waste peels have mental concerns. In addition, although considerable information has been accumulated for the adsorption of single-component dyes by various adsorbents, many industrial situations still result in companies discharging effluents which contain binary dye components. Experimental data on bi-component sorption systems are still very limited in the literature. OII and ACBK for the reasons stated above were selected in this study as the model dyes.

Overall, the systematic research on similar structure dye adsorption onto similar raw materials is still relatively scarce. Orange, pomelo, lemon and finger citron come from the rutaceae family. Therefore, they have similar shape, component and structure. In this work, the waste peels of orange, pomelo, lemon and finger citron (Scheme 1) were investigated for the first time as an alternative low-cost precursor to prepare nanoporous carbon materials (orange peel-based nanoporous carbon, OPC; finger citron peel-based nanoporous carbon, FPC; pomelo peel-based nanoporous carbon, PPC; lemon peel-based nanoporous carbon, LPC) under the same preparation process conditions for the removal of OII and ACBK from aqueous solutions. Two kinds of anionic azo dyes (orange II (OII) and acid chrome blue $\mathrm{K}$ $(\mathrm{ACBK})$ ) with similar structure and different number of functional groups are selected as typical dyed for adsorption onto four types of biomass nanoporous carbons for the first time. The adsorption studies include both equilibrium adsorption isotherms and kinetics, which could provide useful information and insight in this research field.

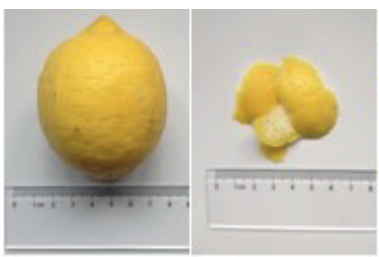

(a) (a')

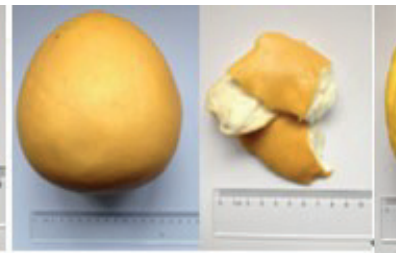

(b) (b')

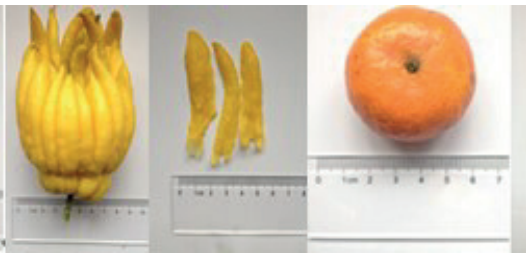

(c) (c') (d)

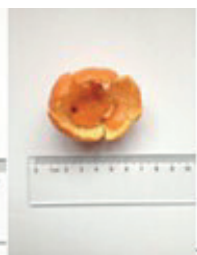

(d')

Scheme 1. Photos of four types of biomass plants

(a)-Lemon; (a')-Lemon peels; (b)- pomelo; (b')- pomelo peels; (c)-Finger citron; (c')-Finger citron peels; (d)-Orange; (d')-orange peels.

\section{EXPERIMENTAL SECTION}

\section{Materials}

Potassium hydroxide $(\mathrm{KOH})$ and hydrochloric acid $(\mathrm{HCl})$ used in this study were purchased from the Sinopharm Chemical Reagent Co., Ltd, China. They were both of analytical grade and were used as received without further purification. An aqueous stock solution of OII and ACBK was prepared by dissolving OII $\left(\mathrm{C}_{16} \mathrm{H}_{11} \mathrm{~N}_{2} \mathrm{NaO}_{4} \mathrm{~S}\right.$, MW: 350.32, Sigma-Aldrich) and ACBK $\left(\mathrm{C}_{16} \mathrm{H}_{9} \mathrm{~N}_{2} \mathrm{Na}_{3} \mathrm{O}_{12} \mathrm{~S}_{3}\right.$, MW: 586.40, Sigma-Aldrich) in distilled water. Distilled water was used to prepare the desired concentrations of dye solutions. The chemical structures of OII and ACBK are shown in Scheme 2. 


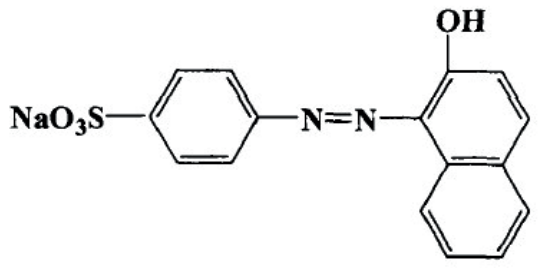

(a)

Scheme 2. Chemical structures of OII (a) and ACBK (b).

\section{Preparation of OPC, PPC, LPC and FPC nanopo- rous carbons}

Four types of nanoporous carbons were prepared by a $\mathrm{KOH}$ activation procedure that was previously proposed by our group (Gong et al., 2013; Dai et al., 2014). In a typical preparation, $2 \mathrm{~g}$ of precursor in the particle size $150 \mu \mathrm{m}$ was mixed with $8 \mathrm{~g}$ of $\mathrm{KOH}$ powder. Hence, the mass ratio of $\mathrm{KOH}$ and biomass peel precursor was $4: 1$ and the resulting mixture was placed into a horizontal pipe reactor ( $50 \mathrm{~mm}$ o.d.) for activating as follows. (i) Nitrogen gas was allowed to flow through the reactor at a rate of $40 \mathrm{~mL} / \mathrm{min}$ and maintained at this flow rate throughout the whole activation process. (ii) The temperature of the reactor was raised to the activation temperature $(1073 \mathrm{~K})$ at a heating rate of $1 \mathrm{~K} / \mathrm{min}$. (iii) The reactor was held at the activation temperature for $40 \mathrm{~min}$. (iv) Finally, it was cooled down to room temperature. The samples thus obtained were washed with distilled water until the filtrate appeared neutral. The final products (OPC, FPC, PPC and LPC) were obtained by heating these samples at $423 \mathrm{~K}$ under vacuum for $24 \mathrm{~h}$.

\section{Nitrogen adsorption}

Specific surface areas and pore volumes were determined by $\mathrm{N}_{2}$ adsorption. An automated adsorption apparatus (Micrometrics, ASAP2020) was used for these measurements. $\mathrm{N}_{2}$ adsorption was carried out at liquid $\mathrm{N}_{2}$ temperature $(77 \mathrm{~K})$. The specific surface areas were calculated using the BET equation by assuming a crosssection area of the nitrogen molecule of $0.162 \mathrm{~nm}$ (Gong et al., 2013). The t-plot method was applied to calculate the micropore volumes and surface areas. The total pore volume was estimated to be the liquid $\mathrm{N}_{2}$ volume at a relative pressure of 0.99 . The pore size distribution was calculated by density functional theory (DFT).

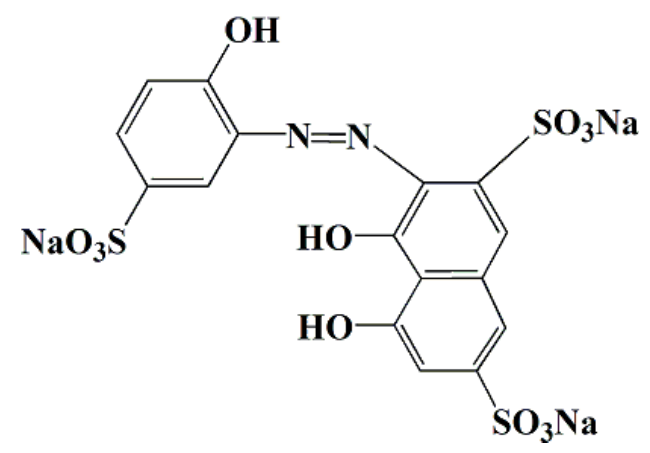

(b)

\section{Batch equilibrium studies}

The equilibrium isotherms of OII and ACBK adsorption on the four types of BNCs were determined by performing adsorption tests in $100 \mathrm{~mL}$ erlenmeyer flasks where $50 \mathrm{~mL}$ of OII and ACBK solutions with different initial concentrations $(50-500 \mathrm{mg} / \mathrm{L})$ were placed in each flask. The $\mathrm{pH}$ value of the solutions was gradually adjusted to 7 by adding small amount of $0.1 \mathrm{M} \mathrm{HCl}$ solution. $0.02 \mathrm{~g}$ of each of the prepared nanoporous carbons, with particle size of $150 \mu \mathrm{m}$, were added to each flask and kept in a shaker with $150 \mathrm{rpm}$ at room temperature $(298 \mathrm{~K})$ for $4 \mathrm{~h}$ to reach equilibrium. The $\mathrm{pH}$ of dye solutions was 7 after the adsorption process, which had no change. Then the samples were filtered and the residual concentrations of OII and ACBK in the filtrate were analyzed by a UV-Visible spectrophotometer (Shimadzu UV-160A) at maximum wavelengths of 485 and $524 \mathrm{~nm}$, respectively. It was found that the calibration curve was very reproducible and linear over the concentration range used in this work. The adsorbed amount of OII and ACBK at equilibrium, $q_{e}(\mathrm{mg} / \mathrm{g})$ was calculated by the following expression:

$$
q_{e}=\frac{\left(C_{o}-C_{e}\right) \cdot V}{W}
$$

where $C_{o}$ and $C_{e}(\mathrm{mg} / \mathrm{L})$ are the initial and equilibrium concentrations of OII and ACBK solution, respectively; $V(\mathrm{~L})$ is the volume of solution, and $W(\mathrm{~g})$ is the weight of nanoporous carbons used. Duplicate experiments were carried out for all the operating variables studied and only the average values were taken into consideration. The average deviation of duplicate results in the units of concentration was found to vary between $\pm 1 \%$.

The batch experiments of binary dye solution were performed with a similar procedure. In a binary system 
with components $\mathrm{A}(\mathrm{OII})$ and $\mathrm{B}$ (ACBK), the measurement is carried out at their maximum absorbance wavelengths $\lambda_{\max 1}$ and $\lambda_{\max 2}$, respectively, giving absorbances of $A_{1}$ and $A_{2}$. Concentrations of dye solution were then estimated quantitatively using the linear regression equations obtained by plotting a calibration curve for each dye over a wide range of concentrations. In a binary dye solution, the concentrations of OII and ACBK were calculated according to the literature (Atar et al., 2011). In a binary system with components $\mathrm{A}$ and $\mathrm{B}$, dye concentrations were calculated by the following equations (Atar et al., 2011):

$$
\begin{gathered}
C_{A}=\frac{k_{B_{2}} A_{1}-k_{B_{1}} A_{2}}{k_{A_{1}} k_{B_{2}}-k_{A_{2}} k_{B_{1}}} \\
C_{B}=\frac{k_{A_{1}} A_{2}-k_{A_{2}} A_{1}}{k_{A_{1}} k_{B_{2}}-k_{A_{2}} k_{B_{1}}}
\end{gathered}
$$

where $k_{A 1}, k_{B 1}, k_{A 2}$, and $k_{B 2}$ are the calibration constants for components $A$ and $B$ at wavelengths $\lambda_{\max 1}$ and $\lambda_{\max 2}$, respectively, giving absorbances of $A_{1}$ and $A_{2} . k_{A l}, k_{B 1}$, $k_{A 2}$, and $k_{B 2}$ for components $A$ and $B$ were obtained using the linear regression equations according to the calibra- tion curve. For binary dye solutions, initial dye concentrations were maintained at 1:1(w/w).

\section{RESULTS AND DISCUSSION}

\section{Material characterization}

As illustrated in Fig. 1, the adsorption and desorption isotherms of $\mathrm{N}_{2}$ at $77 \mathrm{~K}$ for the OPC, FPC, PPC and LPC samples are clearly of type I, according to the IUPAC classification (Dai et al., 2013) of adsorption isotherms. Type I isotherms characteristically show that all of the BNCs investigated in this work are mainly composed of micro nanoporous structure. The specific Brunauer-Emmett-Teller (BET) surface areas of OPC, FPC, PPC and LPC samples are 2289, 1866, 1359 and 1105 $\mathrm{m}^{2} / \mathrm{g}$, respectively. The pore size distributions (PSD) of all the samples were calculated using the density function theory (DFT) model and are shown in Fig. 2. The nanoporous carbon materials of OPC, FPC, PPC and LPC are mainly composed of micropores between $1.1-2.0 \mathrm{~nm}$ and small mesopores peaked at $2.5 \mathrm{~nm}$. The properties of the adsorbents are collected in Table 1. The adsorption performance can be greatly improved by increasing the specific surface area of the adsorbate material.

Table 1. Structural properties of BNCs.

\begin{tabular}{cccccc}
\hline Samples & $\begin{array}{c}\text { SBET } \\
\left(\mathbf{m}^{\mathbf{2}} \mathbf{g}\right)\end{array}$ & $\begin{array}{c}\mathbf{V}_{\text {total }} \\
(\mathbf{m L} / \mathbf{g})\end{array}$ & $\begin{array}{c}\mathbf{V}_{\text {meso }} \\
(\mathbf{m L} / \mathbf{g}, \mathbf{\%})\end{array}$ & $\begin{array}{c}\mathbf{V}_{\text {mic }} \\
(\mathbf{m L} / \mathbf{g}, \mathbf{\%})\end{array}$ & $\begin{array}{c}\text { Average pore } \\
\text { diameter }(\mathbf{n m})\end{array}$ \\
\hline LPC & 1105 & 0.74 & $0.22(30)$ & $0.52(70)$ & 1.68 \\
PPC & 1359 & 0.81 & $0.17(22)$ & $0.64(78)$ & 1.48 \\
FPC & 1866 & 1.50 & $0.41(26)$ & $1.19(74)$ & 2.18 \\
OPC & 2289 & 1.48 & $0.48(32)$ & $1.00(68)$ & 2.07 \\
\hline
\end{tabular}

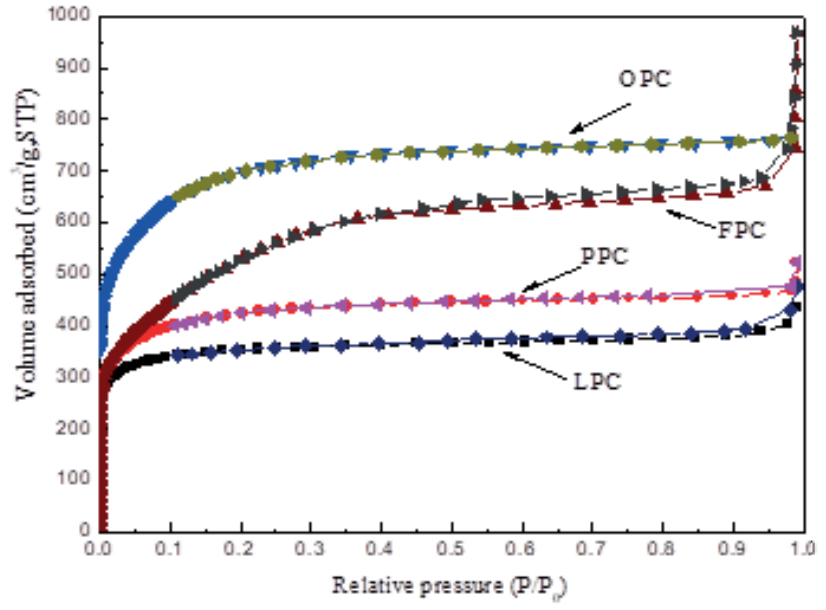

Fig. 1. Adsorption isotherms of $\mathrm{N}_{2}$ at $77 \mathrm{~K}$ on LPC, PPC, FPC and OPC samples, respectively.

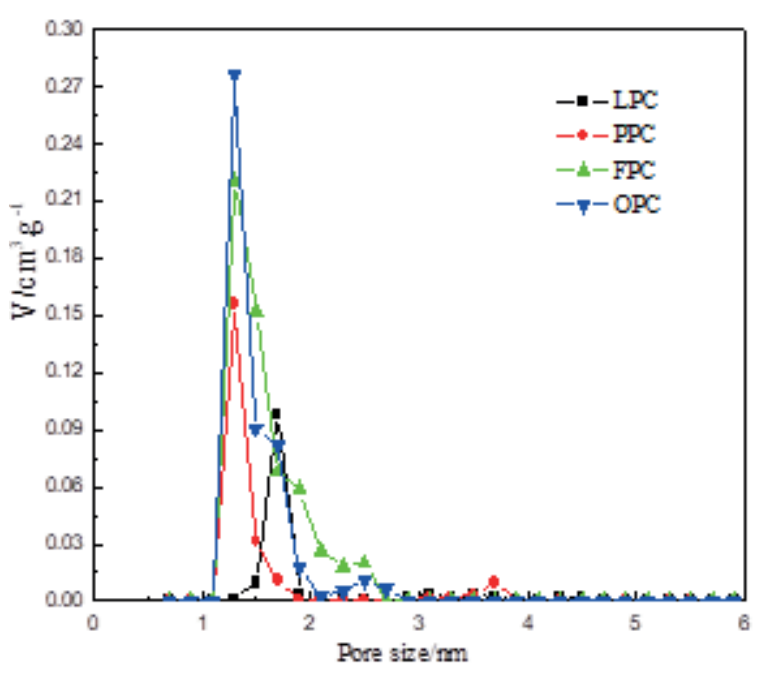

Fig. 2. Pore size distribution of LPC, PPC, FPC and OPC samples, respectively. 


\section{Adsorption isotherms}

Equilibrium data, commonly known as adsorption isotherms, describe how the adsorbate interacts with adsorbents, and give a comprehensive understanding of the nature of interaction. It is important to optimize the design of an adsorption system (Royer et al., 2009). The parameters obtained from the different models provide important information on the surface properties of the adsorbent and its affinity for the adsorbate. Several isotherm equations have been developed and employed for such analysis and the three important isotherms, the Langmuir, Freundlich and Temkin isotherms are applied in this study. The adsorption isotherms of OII and ACBK at $298 \mathrm{~K}$ on the OPC, FPC, PPC and LPC at a solid/liquid ratio of $0.4 \mathrm{~g} / \mathrm{L}$ in single and binary solutions are presented in Fig. 3, Fig. 4 and Fig. 5, respectively.

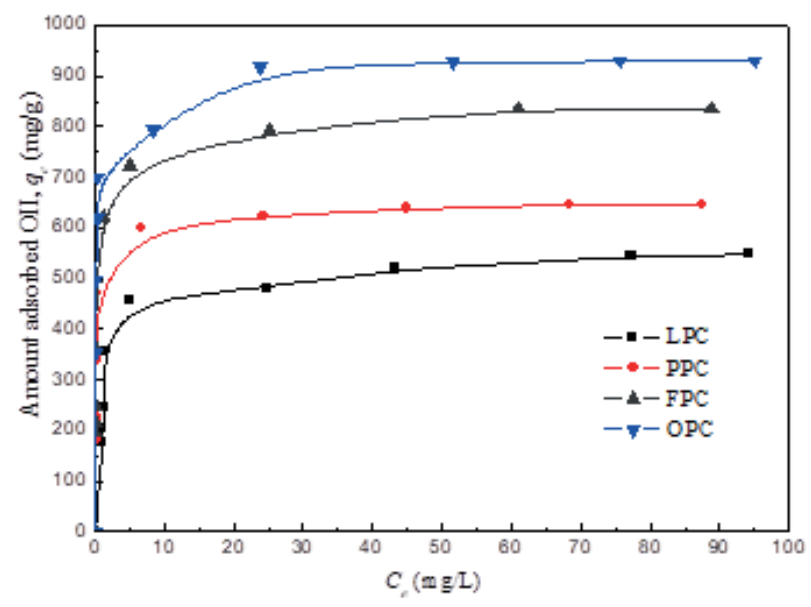

Fig. 3. Adsorption isotherms of OII onto LPC, PPC, FPC and OPC in the single system. (t: $4 \mathrm{~h}, \mathrm{pH}: 7$, dose: $0.4 \mathrm{~g} / \mathrm{L}, \mathrm{T}: 298 \mathrm{~K}$, Particle size: $150 \mu \mathrm{m}$, Initial concentrations: $50-500 \mathrm{mg} / \mathrm{L})$.

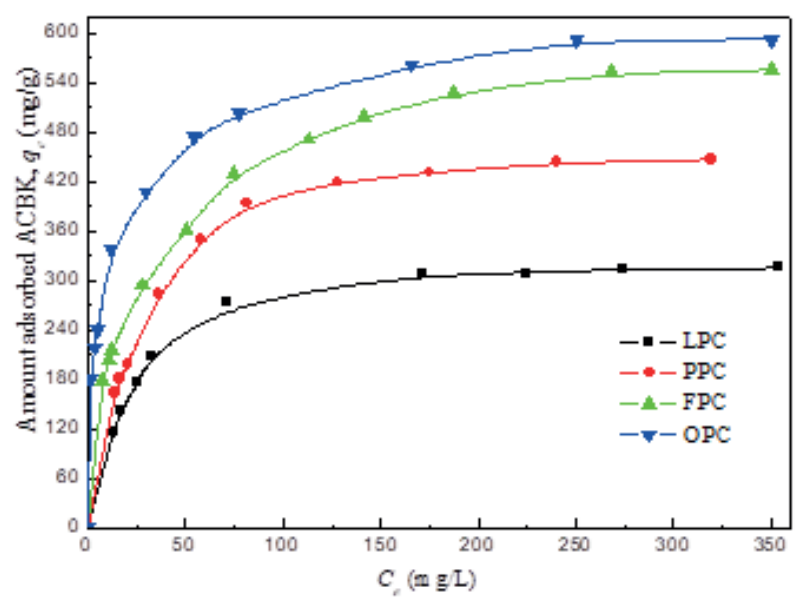

Fig. 4. Adsorption isotherms of ACBK onto LPC, PPC, FPC and OPC in the single system. (t: $4 \mathrm{~h}, \mathrm{pH}: 7$, dose: $0.4 \mathrm{~g} / \mathrm{L}, \mathrm{T}: 298 \mathrm{~K}$, Particle size: $150 \mu \mathrm{m}$, Initial concentrations: $50-500 \mathrm{mg} / \mathrm{L}$ ).

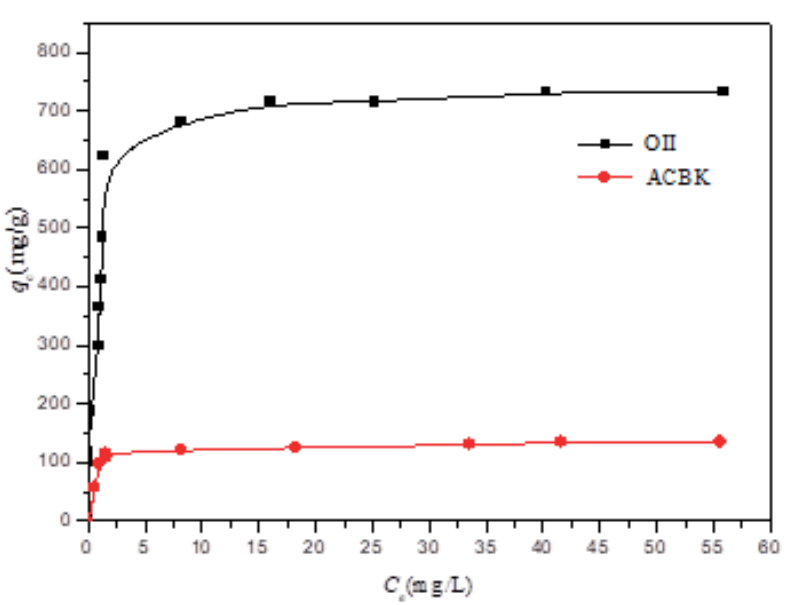

Fig. 5. Adsorption isotherms of OII and ACBK onto OPC in the binary system. (t: 4 h, pH: 7, dose: 0.4 g/L, T: 298 K, Particle size: $150 \mu \mathrm{m}$, Initial concentrations: $50-500 \mathrm{mg} / \mathrm{L}$ ).

The Langmuir adsorption isotherm describes quantitatively the formation of a monolayer of adsorbate on the outer surface of the adsorbent and, after that, no further adsorption takes place. Thereby, the Langmuir represents the equilibrium distribution of dye molecules between the solid and liquid phases (Langmuir, 1918; Hameed, 2009; El-Geundi, 1991; Afkhami et al., 2009). The Langmuir isotherm is valid for monolayer adsorption onto a surface containing a finite number of identical sites. The model assumes uniform energies of adsorption onto the surface and no transmigration of adsorbate in the plane of the surface. Based upon these assumptions, the linear form of Langmuir's isotherm model is represented as follows:

$$
\frac{C_{e}}{q_{e}}=\frac{1}{q_{L} \cdot K_{L}}+\left(\frac{1}{q_{L}}\right) \cdot C_{e}
$$

where $q_{L}(\mathrm{mg} / \mathrm{g})$ is the Langmuir maximum uptake of OII and ACBK per unit mass of adsorbent, $K_{L}(\mathrm{~L} / \mathrm{mg})$ is the Langmuir constant related to the rate of adsorption.

The Freundlich isotherm is an empirical equation assuming that the adsorption process takes place on a heterogeneous surface through a multilayer adsorption mechanism and adsorption capacity is related to the concentration of dye at equilibrium (Mafra et al, 2013). The Freundlich equation is given as:

$$
\ln q_{e}=\ln K_{f}+\left(\frac{1}{n}\right) \cdot \ln C_{e}
$$

where $K_{f}$ and $n$ are Freundlich constants, with $n$ indicating the favorableness of the adsorption process and $K_{f}$ the adsorption capacity of the adsorbent. $K_{f}$ can be defined as the adsorption or distribution coefficient and it represents the quantity of dye adsorbed onto activated carbon adsorbent for a unit equilibrium concentration. 
The slope $1 / \mathrm{n}$, ranging between 0 and 1 , is a measure of adsorption intensity or surface heterogeneity, becoming more heterogeneous as its value gets closer to zero.

The Temkin isotherm contains a factor that explicitly takes into account the adsorbent-adsorbate interactions. By ignoring the extremely low and large value of concentrations, the model assumes that the heat of adsorption (a function of temperature) of all molecules in the layer should decrease linearly rather than logarithmically with coverage (Dotto et al, 2013). The linear form of Temkin isotherm is expressed as:

$$
q_{e}=B \ln A+B \ln C_{e}
$$

where $B$ is the Temkin constant related to the heat of adsorption and $A$ is the equilibrium binding constant (L/mg). The constants $A$ and $B$ can be determined by a plot of $q_{e}$ versus $\ln C_{e}$.

The adsorption isotherms were L-curve in both dye systems (Fig. 3-5). Hence we could say that the adsorption mechanisms were not affected under the conditions of competition. The L-type curve shows the higher affinity of the adsorbate for the adsorbent. The calculated constants according to the two isotherm equations along with $R^{2}$ values (standard deviation) are presented in Table 2. This table shows that the Langmuir isotherm gives the best fits with $R^{2}>0.998$. The good fit to the Langmuir model for the dyes also suggests that the adsorption is limited to a monolayer coverage and the surface is relatively homogeneous. On the other hand, for OII and ACBK dyes, the maximum monolayer adsorption capacity $\left(q_{L}\right)$ is significantly higher on OPC. The uptake capacity of OII is also significantly higher than that of the ACBK (approximately 1.5-fold higher). This may be due to the different molecular sizes and functional groups of the two dyes. OII and ACBK are ideally planar molecules and therefore can easily adsorb on porous carbon by $\pi-\pi$ stacking interactions between the aromatic backbone of the dye and the hexagonal skeleton of porous carbon. As shown in Scheme 2, ACBK has more functional groups (3 hydroxyl and 3 sulfonic acid groups) than OII (1 hydroxyl and 1 sulfonic acid group), the relatively complicated structure of ACBK has high steric hindrance in the pore channels of the carbon materials. Thus, OII shows higher uptake capacities than ACBK. The result suggested that the adsorption mechanism was monolayer coverage on the surface of the adsorbent. In addition, the values of $q_{0}$ evaluated from the Langmuir model were close to the experimental values of $q_{\mathrm{e}}$. On the other hand, for OII and ACBK the maximum monolayer adsorption capacities $\left(q_{L}\right)$ are significantly higher on OPC and vary in the order of $\mathrm{OPC}>\mathrm{FPC}>\mathrm{PPC}>\mathrm{LPC}$. Thus, it is predicted that the dye uptake capacity of nanoporous carbons is significantly higher with increased surface area. To test the dependence of dye capacity on carbon structure, the maximum adsorption capacities were in turn correlated with the specific surface area, pore volume, and nominal pore size. Linear correlation coefficients of OII and ACBK on OPC, FPC, PPC and LPC obtained are 0.9937 , $0.956,0.821$ and $0.9512,0.919,0.734$, respectively. It seems that specific surface area exerts the largest effect and the correlation is shown in Fig. 6. The adsorption capacities of OII and ACBK on the four types of BNCs in this work are summarized in Table 3, together with those of the other nanoporous carbons. It is clear that the adsorption capacity of OPC is superior to the other previously reported nanoporous carbon materials (Ma et al., 2015; Guzel et al., 2014; Rodríguez et al., 2009; Yan et al., 2012; Wang, 2014).

Table 2. Constants and correlation coefficients of OII and ACBK adsorption from single solutions

\begin{tabular}{|c|c|c|c|c|c|c|c|c|c|c|}
\hline \multirow[b]{2}{*}{ BNCs } & \multirow[b]{2}{*}{ Dye } & \multicolumn{3}{|c|}{ Langmuir } & \multicolumn{3}{|c|}{ Freundlich } & \multicolumn{3}{|c|}{ Temkin } \\
\hline & & $q L(m g / g)$ & $\begin{array}{c}\text { KL } \\
\text { (L/mg) }\end{array}$ & $\mathbf{R 2}$ & $\begin{array}{c}\mathbf{K f} \\
(\mathbf{L} / \mathbf{g})\end{array}$ & $\mathbf{n}$ & $\mathbf{R 2}$ & $\begin{array}{c}\text { A } \\
\text { (L/mg) }\end{array}$ & B & $\mathbf{R 2}$ \\
\hline \multirow{2}{*}{ LPC } & OII & 556 & 0.51 & 0.9992 & 240 & 4.96 & 0.7217 & 31.85 & 71.45 & 0.8200 \\
\hline & ACBK & 338 & 0.05 & 0.9993 & 68 & 3.53 & 0.8853 & 0.72 & 60.94 & 0.9400 \\
\hline \multirow{2}{*}{ PPC } & OII & 645 & 3.12 & 0.9999 & 375 & 6.89 & 0.7593 & 1366 & 58.31 & 0.8510 \\
\hline & ACBK & 488 & 0.04 & 0.9987 & 77 & 2.99 & 0.9004 & 0.45 & 98.09 & 0.9445 \\
\hline \multirow{2}{*}{ FPC } & OII & 840 & 2.7 & 0.9999 & 462 & 5.76 & 0.8633 & 659 & 81.69 & 0.9527 \\
\hline & ACBK & 595 & 0.04 & 0.9982 & 100 & 3.18 & 0.9729 & 0.64 & 107.40 & 0.9902 \\
\hline \multirow{2}{*}{ OPC } & OII & 935 & 2.65 & 0.9998 & 630 & 9.75 & 0.9081 & 244 & 65.95 & 0.9618 \\
\hline & ACBK & 606 & 0.10 & 0.9986 & 173 & 4.34 & 0.9662 & 4.61 & 83.33 & 0.9895 \\
\hline
\end{tabular}


Table 3. Comparison of the maximum uptake capacities of OII and ACBK dyes on various nanoporous carbons.

\begin{tabular}{cccc}
\hline Dye & Adsorbent & $\begin{array}{c}\text { Maximum } \\
\text { monolayer uptake } \\
\text { capacities (mg/g) }\end{array}$ & Reference \\
\hline \multirow{6}{*}{ OII } & OPC & 930 & this work \\
& FPC & 835 & this work \\
& PPC & 645 & this work \\
& LPC & 547 & this work \\
& BPAC & 333 & 22 \\
& TWNC & 313 & 23 \\
& AC & 568 & 24 \\
& OPC & 592 & this work \\
& FPC & 555 & this work \\
& PPC & 446 & this work \\
& LPC & 315 & this work \\
& AC & 152 & 25 \\
& JAC & 240 & 26 \\
\hline
\end{tabular}

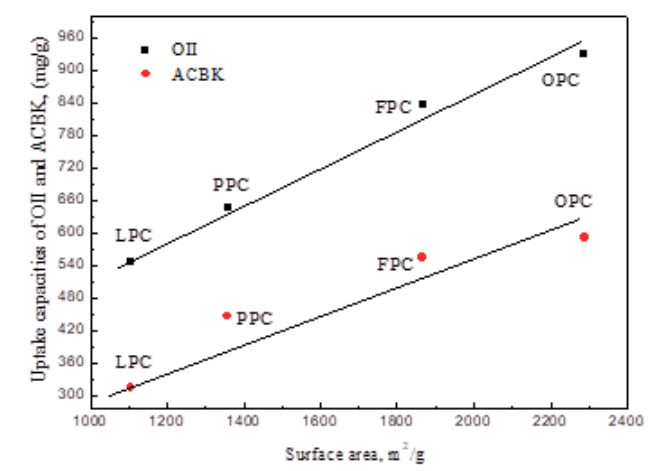

Fig. 6. Correlation of OII and ACBK capacities with specific surface area of nanoporous carbons.

The equations of a competitive Langmuir model (Choy et al., 2000) are as follows:

$$
\begin{aligned}
& q_{e 1}=\frac{q_{\max 1} K_{L 1} C_{e 1}}{1+K_{L 1} C_{e 1}+K_{L 2} C_{e 2}} \\
& q_{e 2}=\frac{q_{\max 2} K_{L 2} C_{e 2}}{1+K_{L 1} C_{e 1}+K_{L 2} C_{e 2}}
\end{aligned}
$$

where $K_{L 1}$ and $K_{L 2}$ are the Langmuir constants of the adsorbates 1 and 2, $q_{\max 1}$ and $q_{\max 2}$ are the maximum adsorption capacity of the adsorbates 1 and 2 .

For binary dye adsorption systems (Fig. 5), the adsorption capacities of OII and ACBK onto OPC were reduced from $930 \mathrm{mg} / \mathrm{g}$ (single system) to $690 \mathrm{mg} / \mathrm{g}$ (binary system) and from $555 \mathrm{mg} / \mathrm{g}$ (single system) to $130 \mathrm{mg} / \mathrm{g}$ (binary system), respectively, at $\mathrm{pH} 7$ because of the highly competition for active sites between two types of dye molecules in the binary system. OII has a lower molecular weight than ACBK and the adsorption capacity of OII is higher than that of ACBK at $\mathrm{pH}$ 7. The experimental data in the binary systems were applied to the competitive Langmuir equations (Table 4). The correlation coefficients in the binary system were lower than in single dye system. We can say that the adsorbent surface is homogeneous and there is no interaction between the adsorbed molecules. These are applied to real systems due to the effect of surface heterogeneity and interaction between azo dye molecules.

\section{Adsorption kinetics}

The kinetics of adsorption are important because this is what controls the efficiency of the process and the time to reach equilibrium. It also describes the rate of adsorbate uptake on nanoporous carbons. In order to identify the potential rate-controlling steps involved in the process of adsorption, three kinetic models were studied and used to fit the experimental data from the adsorption of dyes onto nanoporous carbons. These models are the pseudo-first-order (Dotto et al., 2013), pseudo-second-order (Ho and McKay, 1998) and intra-particle diffusion models (Annadurai et al., 2002). These models can be expressed as:

Pseudo-first order model:

$$
\ln \left(q_{e}-q_{t}\right)=\ln \left(q_{e}\right)-K_{1} t
$$

Pseudo-second order model:

$$
\frac{t}{q_{t}}=\frac{1}{K_{2} q_{e}}+\frac{t}{q_{e}}
$$

Intra-particle diffusion model:

$$
q_{t}=K_{3} t^{1 / 2}
$$

where $q_{e}$ and $q_{t}(\mathrm{mg} / \mathrm{g})$ are the uptake of OII and ACBK at equilibrium and at time $\mathrm{t}(\mathrm{min})$, respectively, $K_{I}$ $(1 / \mathrm{min})$ is the adsorption rate constant, $K_{2}(\mathrm{~g} / \mathrm{mg} \cdot \mathrm{min})$ is the rate constant of the second-order equation, $K_{3}$ $\left(\mathrm{mg} / \mathrm{g} \cdot \mathrm{min}^{1 / 2}\right)$ is the intra-particle diffusion rate constant.

In order to quantitatively compare the applicability of different kinetic models in fitting to data, a normalized standard deviation, $\triangle q(\%)$, was calculated as below:

$$
\Delta q(\%)=\frac{\left(q_{e, \exp }-q_{e, \text { cal }}\right)}{q_{e, \exp }} \times 100 \%
$$

The effects of contact time on adsorption capacities of the four types of BNCs for OII and ACBK from single and binary dye solutions are shown in Fig. 7, Fig. 8 and Fig. 9, respectively. These figures show that the adsorption capacities for OII and ACBK increase with the increase of contact time, and the adsorption reaches equilibrium within about $1 \mathrm{~h}$. The saturation capacities of 


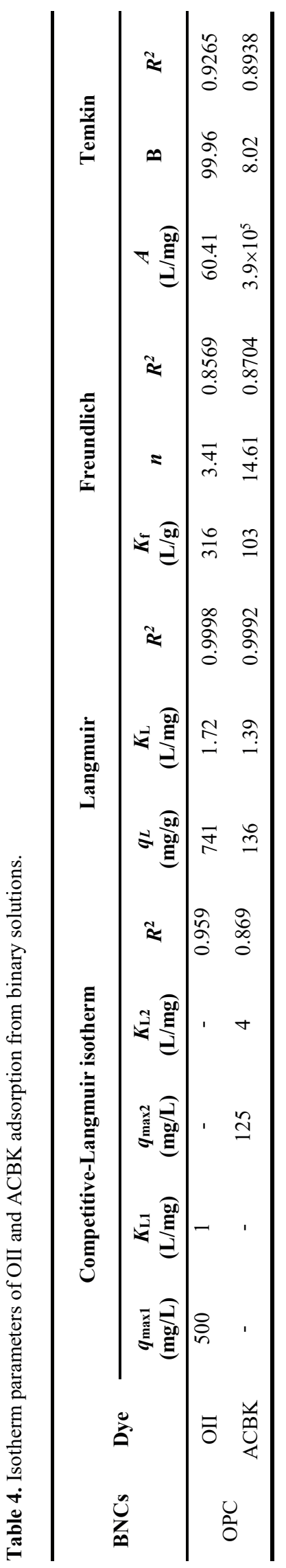

OII and ACBK onto OPC, FPC, PPC and LPC in the single dye solution are $930,835,645,547 \mathrm{mg} / \mathrm{g}$ and 592 , $555,446,315 \mathrm{mg} / \mathrm{g}$ at room temperature $(298 \mathrm{~K}), 4 \mathrm{~h}$ contact time, $450 \mathrm{mg} / \mathrm{L}$ initial concentration, $\mathrm{pH} 7$ and $0.4 \mathrm{~g} / \mathrm{L}$ adsorbent dose. For single and binary dye adsorption systems, the adsorption capacities of OII and ACBK were reduced from $930 \mathrm{mg} / \mathrm{g}$ (single system) to $689 \mathrm{mg} / \mathrm{g}$ (binary system) and from $592 \mathrm{mg} / \mathrm{g}$ (single system) to $120 \mathrm{mg} / \mathrm{g}$ (binary system), respectively, at $\mathrm{pH}$ 7 because of the competition for active sites between the two types of dye molecules in the binary system. The capacity is constant when all the parameters are fixed, and with the evolution of time, the uptake or adsorbed amount may change. The fast adsorption at the initial stage may be due to the availability of the uncovered surface area and the remaining active sites on the adsorbent.

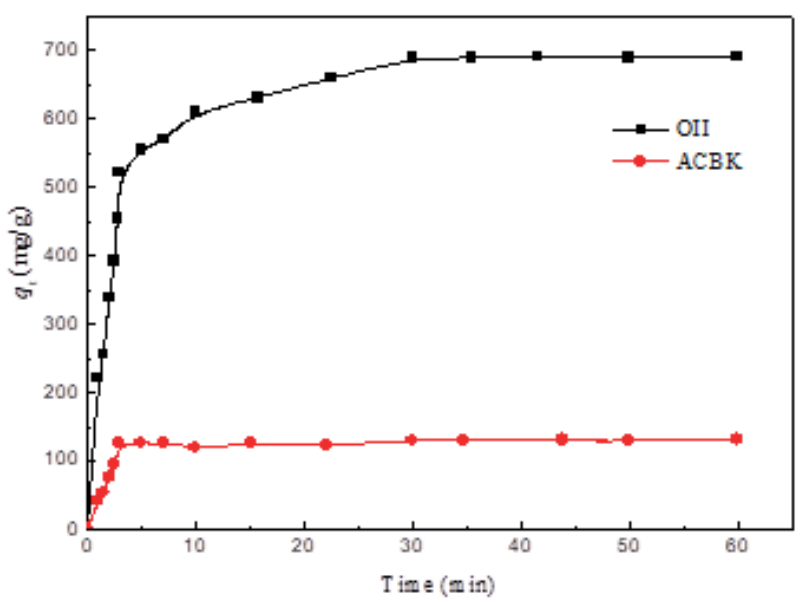

Fig. 7. Effect of contact time on the adsorption capacities of ACBK on LPC, PPC, FPC and OPC in the single system.

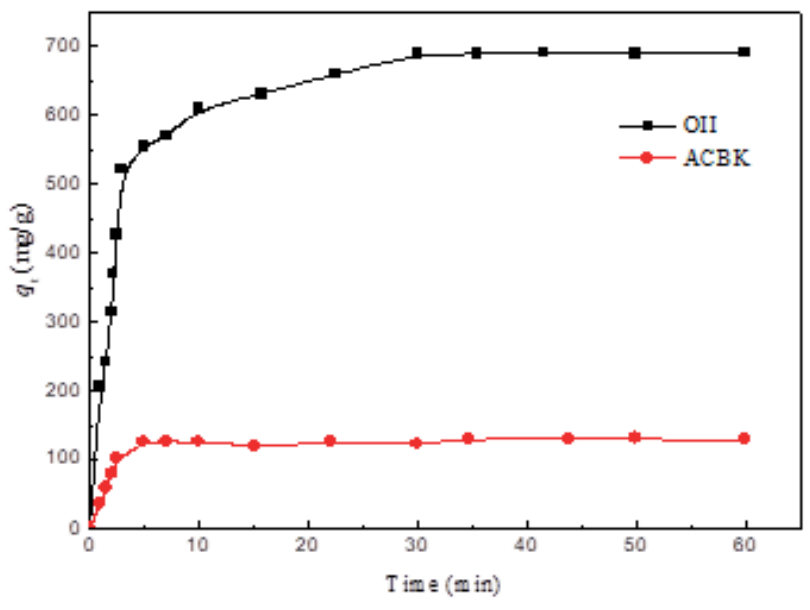

Fig. 8. Effect of contact time on the adsorption capacities of OII on LPC, PPC, FPC and OPC in the single system. 


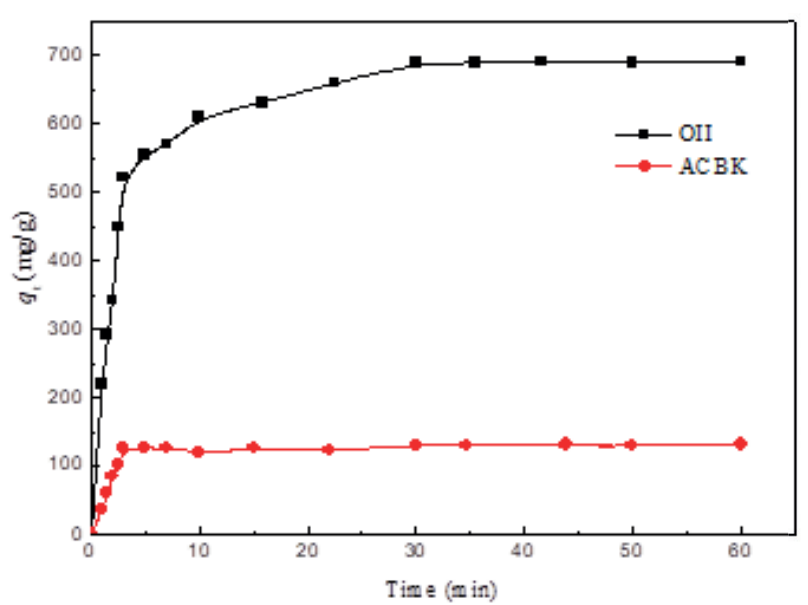

Fig. 9. Effect of contact time on the adsorption capacities of OII and ACBK on OPC in the binary system.

The experimental kinetic data of OII and ACBK, calculated from Eqs. 9, 10 and 11, were correlated by three kinetic models: pseudo-first order, pseudo-second order and intra-particle diffusion models. The calculated constants of the three kinetic equations, along with $R^{2}$ values at different temperatures, are presented in Table 5 and 6. As seen in the Tables, there is a large difference between the experimental and calculated adsorption capacity values when the pseudo-first order model was applied. However, high $R^{2}$ values $(>0.999)$ are obtained with the linear plot of $t / q_{\mathrm{t}}$ versus $t$, suggesting second order adsorption kinetics. Additionally, the pseudo-second order kinetic model is in a good agreement with the experimental and calculated adsorption capacity values $\Delta q(\%)$. If the intra-particle diffusion is the mechanism of the adsorption process, then the plot of $q_{t}$ versus $t^{1 / 2}$ will be linear and if the plot passes through the origin, then the rate limiting process is only due to the intra-particle diffusion. Otherwise, some other mechanism along with intraparticle diffusion is also

involved (Bhattacharyya and Sharma, 2005). However, as shown in Figs. 10 and 11, the plots are not linear over the whole time range and, instead, can be separated into multi-linear curves, illustrating that multiple stages were involved in the adsorption process. The first straight portion was attributed to the macropore diffusion (phase I) and the second linear portion was attributed to micro-pore diffusion (phase II). The results indicated that the adsorption of OII and ACBK dyes onto BNCs involved more than one process, and the intra-particle transport is not the rate-limiting step. This finding is similar to that made in previous works (Bhattacharyya and Sharma, 2004; Mahmoudi et al., 2012; Emad et al., 2006).

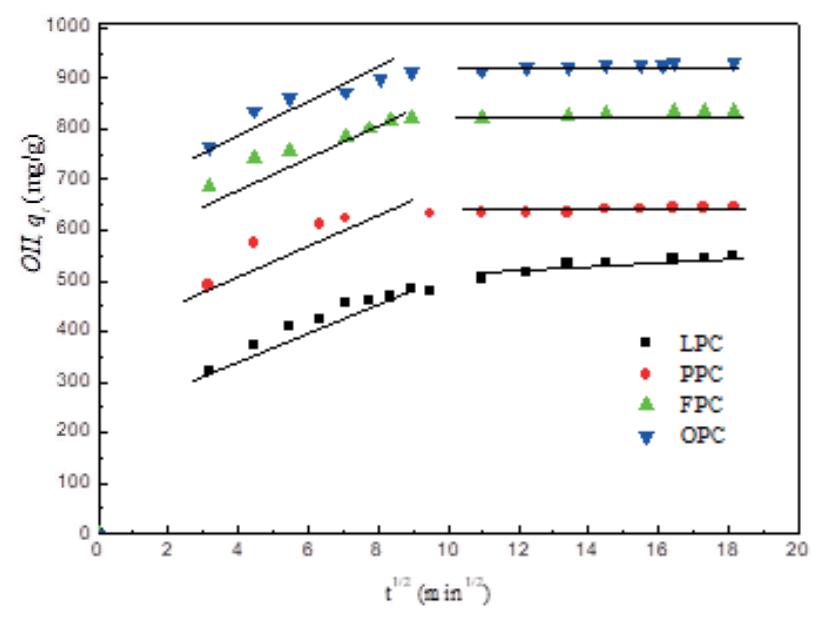

Fig. 10. Weber-Morris intra-particle diffusion plots for the adsorption of OII on LPC, PPC, FPC and OPC, respectively.

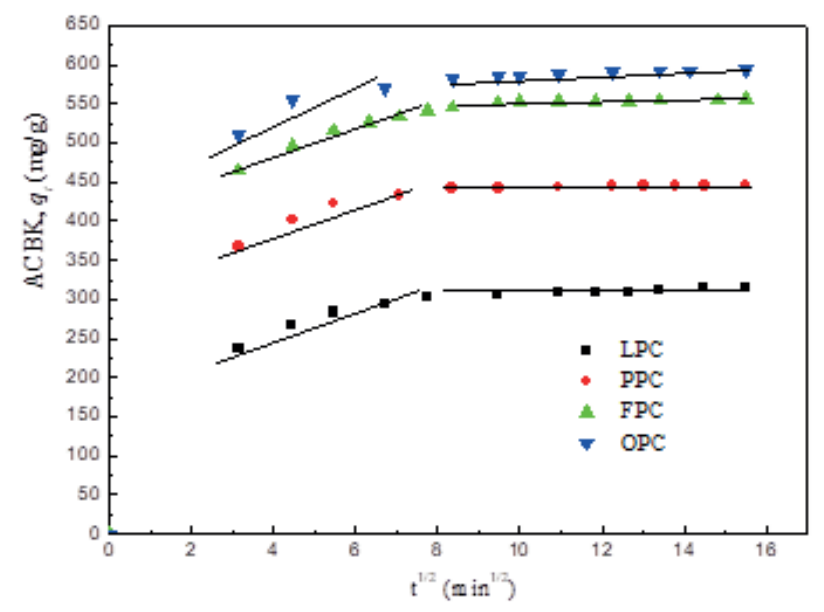

Fig. 11. Weber-Morris intra-particle diffusion plots for the adsorption of ACBK on LPC, PPC, FPC and OPC, respectively.

\section{CONCLUSION}

In summary, LPC, PPC, FPC and OPC with a high surface area were synthesized from solid waste, which is a natural, abundantly available, and constantly renewable source. Adsorption parameters for the Langmuir, Freundlich and Temkin isotherms were determined and the equilibrium data were best described by the Langmuir isotherm model, with maximum equilibrium adsorption capacity of $930 \mathrm{mg} / \mathrm{g}$ (OII) and $592 \mathrm{mg} / \mathrm{g}$ (ACBK), respectively. The adsorption kinetics can be successfully fitted to a pseudo-second-order kinetic model. It suggests that the BNCs could be employed as a promising low-cost adsorbent for removal of OII and 


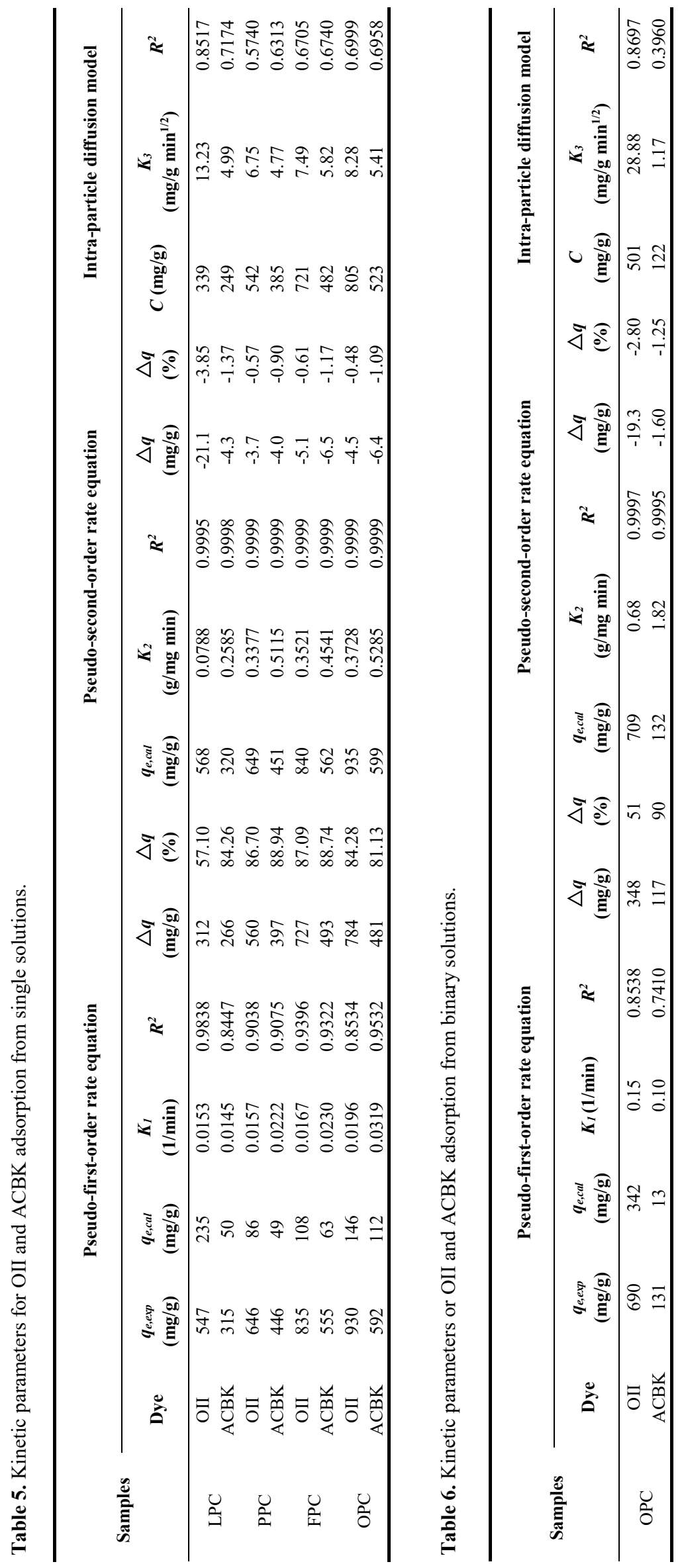


ACBK from single and binary dye solutions. The kinetic and equilibrium data will be useful for fabrication and designing dye wastewater treatments. Because of their huge adsorption capacity, such materials can act as a promising catalyst for next-generation fuel cells and still have vast unexplored potential in the fields of super capacitors, water purification, $\mathrm{CO}_{2}$ adsorption, and hydrogen storage. We believe that our as-synthesized carbon will certainly be a trend setter and have greater economic ramifications by creating value-added materials from waste, which otherwise would become an environmental burden.

\section{ACKNOWLEDGMENTS}

This work was supported by the Public Projects of Zhejiang Province of China (No. 2015C31083), Zhejiang Qianjiang Talent Project (No. QJD1302014) and The Financial Support by Open Research Fund of Top Key Discipline of Chemistry in Zhejiang Provincial Colleges and Key Laboratory of the Ministry of Education for Advanced Catalysis Materials (Zhejiang Normal University).

\section{REFERENCES}

Atar, N., Olgun, A., Wang, S. B., Liu, S. M., Adsorption of anionic dyes on boron industry waste in single and binary solutions using batch and fixed-bed systems. Journal of Chemical \& Engineering Data, 56(3), 508-516 (2011).

Afkhami, A., Madrakian, T., Amini, T., Mo(VI) and W(VI) removal from water samples by acid-treated high area carbon cloth. Desalination, 243, 258-264 (2009).

Annadurai, G., Juang, R. S., Lee, D. J., Use of cellulose-based wastes for adsorption of dyes from aqueous solutions. Journal of Hazardous Materials, 92(3), 263-274 (2002).

Bhattacharyya, K. G., Sharma, A., Kinetics and thermodynamics of methylene blue adsorption on neem (azadirachta indica) leaf powder. Dyes and Pigments, 65(1), 51-59 (2005).

Bhattacharyya, K. G., Sharma, A., Adsorption of $\mathrm{Pb}$ (II) from aqueous solution by azadirachta indica (neem) leaf powder. Journal of Hazardous Materials, 113(1-3), 97-109 (2004).

Choy, K. K. H., Porter, J. F., McKay, G., Langmuir isotherm models applied to the multicomponent sorption of acid dyes from effluent onto activated carbon. Journal of Chemical and Engineering Data, 45(4), 575-584 (2000).

Dai, W., Chen, J. R., Ma, N., Preparation of activated carbon with finger citron residue. China Patent ZL, CN101844764A (2010).

Dai, W., Gong, R., Hu, J., Zhou, L. M., Thiophene capture by an oxidation-modified activated carbon derived from bergamo. Separation Science and Technology, 49(3), 367-375 (2014).

Dai, W., Hu, J., Zhou, L. M., Li, S., Hu, X., Huang, H., Removal of dibenzothiophene with composite adsorbent MOF-5/Cu(I). Energy \& Fuels. 27, 816-821 (2013).
El-Geundi, M. S., Color removal from textile effluents by adsorption techniques. Water Research, 25, 271-273 (1991).

Dotto, G. L., Vieira, M. L. G., Esquerdo, V. M., Equilibrium and thermodynamics of azo dyes biosorption onto spirulina platensis. Brazilian Journal of Chemical Engineering, 1, 13-27(2013).

Emad, N. E. Q., Allen, S. J., Walker, G. M., Adsorption of methylene blue onto activated carbon produced from steam activated bituminous coal: A study of equilibrium adsorption isotherm. Chemical Engineering Journal, 124(1-3), 103-110 (2006).

Gong, R., Ye, J. J., Dai, W., Yan, X. Y., Hu, J., Hu, X., Li, S., Huang, H., Adsorptive removal of methyl orange and methylene blue from aqueous solution with finger-citron-residue-based activated carbon. Industrial \& Engineering Chemistry Research, 52, 14297-14303 (2013).

Guzel, F., Saygili, H., Saygili, G. A., Koyuncu, F., Elimination of anionic dye by using nanoporous carbon prepared from an industrial biowaste. Journal of Molecular Liquids, 194, 130-140 (2014).

Hu, L. H., Wu, F. Y., Lin, C. T., Khlobystov, A. N., Li, L. J., Graphene-modified $\mathrm{LiFePO}_{4}$ cathode for lithium ion battery beyond theoretical capacity. Nature Communications, 4, 1687 (2013).

Hu, J., Yu, H. J., Dai, W., Yan, X. Y., Hu, X., Huang, H., Enhanced adsorptive removal of hazardous anionic dye "congo red" by a $\mathrm{Ni} / \mathrm{Cu}$ mixed-component metal-organic porous material. RSC Advances, 4(66), 35124-35130 (2014) .

Hameed, B. H., Spent tea leaves: A new non-conventional and low-cost adsorbent for removal of basic dye from aqueous solutions. Journal of Hazardous Materials, 161, 753-759 (2009).

Ho, Y. S., McKay, G., Sorption of dye from aqueous solution by peat. Chemical Engineering Journal, 70(2), 115-124(1998).

Kharat, D. S., Preparing agricultural residue based adsorbents for removal of dyes from effluents - a review. Brazilian Journal of Chemical Engineering, v. 1, 1 (2015)

Lv, Y. K., Gan, L. H., Liu, M. X., Xiong, W., Xu, Z. J., Zhu, D. Z., Wright, D. S., A self-template synthesis of hierarchical porous carbon foams based on banana peel for supercapacitor electrodes. Journal of Power Sources, 209, 152-157 (2012).

Langmuir, I., The adsorption of gases on plane surfaces of glass, mica and platinum. Journal of the American Chemical Society, 40, 1361-1402 (1918).

Ma, J. F., Huang, D. Q., Zou, J., Li, L. Y., Kong, Y., Komarneni, S., Adsorption of methylene blue and orange II pollutants on activated carbon prepared from banana peel. Journal of Porous Materials, 22(2), 301-311 (2015).

Mahmoudi, K., Hamdi, N., Kriaa, A., Srasra, E., Adsorption of methyl orange using activated carbon prepared from lignin by $\mathrm{ZnCl}_{2}$ treatment. Russian Journal of Physical Chemistry A, 86(8), 1294-1300 (2012).

Mafra, M. R., Igarashi-Mafra, L., Zuim, D. R., Adsorption of removal brilliant blue on an orange peel adsorbent. Brazilian Journal of Chemical Engineering, v. 3, 657-65 (2013). 
Ofomaja, A. E., Ho, Y. S., Effect of temperatures and $\mathrm{pH}$ on methyl violet biosorption by mansonia wood sawdust. Bioresource Technology, v99(13), 5411-5417 (2008).

Royer, B., Cardoso, N. F., Lima, E. C., Vaghetti, J. C. P., Simon, N. M., Calvete, T., Veses, R. C., Applications of brazilian pine-fruit shell in natural and carbonized forms as adsorbents to removal of methylene blue from aqueous solutions--kinetic and equilibrium study. Journal of Hazardous Materials, 164(2-3), 1213-1222 (2009).

Rodríguez, A., García, J., Ovejero, G., Mestanza, M., Adsorption of anionic and cationic dyes on activated carbon from aqueous solutions: Equilibrium and kinetics. Journal of Hazardous Materials, 172(2-3), 1311-1320 (2009).

Sun, H. Q., Wang, Y. X., Liu, S. Z., Ge, L., Wang, L., Zhu, Z. H., Wang, S. B., Facile synthesis of nitrogen doped reduced graphene oxide as a superior metal-free catalyst for oxidation. Chemical Communications, 49, 9914-9916 (2013).

Wu, X. L., Wen, T., Guo, H. L., Yang, S. B., Wang, X. K., Xu, A. W., Biomass-derived sponge-like carbonaceous hydrogels and aerogels for supercapacitors. ACS Nano., 7(4), 3589-3597 (2013).
Wang, H. W., Xu, Z. W., Kohandehghan, A., Li, Z., Cui, K., Tan, X. H., Stephenson, T. J., Kingondu, C. K., Holt, C. M. B., Olsen, B. C., Tak, J. K., Harfield, D., Anyia, A. O., Mitlin, D., Interconnected carbon nanosheets derived from hemp for ultrafast supercapacitors with high energy. ACS Nano, 7(6), 5131-5141 (2013).

Wu, Z. Y., Liang, H. W., Li, C., Hu, B. C., Xu, X. X., Wang, Q., Chen, J. F., Yu, S. H., Dyeing bacterial cellulose pellicles for energetic heteroatom doped carbon nanofiber aerogels. Nano Research, 7, 1861-1872 (2014).

Wu, Z. Y., Li, C., Liang, H. W., Chen, J. F., Yu, S. H., Ultralight, flexible, and fire-resistant carbon nanofiber aerogels from bacterial cellulose. Angewandte Chemie International Edition, 52(10), 2925-2529 (2013).

Wang, D. H., Study on adsorption behavior of acid chrome blue $\mathrm{K}$ by activated carbon. Journal of Weinan Normal University, 29, 29-32 (2014).

Yan, Z. L., Wei, Z., Song, X. L.,Wang, W., Shi, J., Studies on adsorption properties of activated carbon for malachite green and acid chrome blue K. Journal of Tianjin Agricultural University, 19, 45-47 (2012). 